To live in the House of the King, to serve in the House of the Empire: Society, Culture and Politics in the Domestic Universe of the Portuguese Royal House and the Brazilian Imperial House (1808-1840)

\title{
Morar na Casa do Rei, servir na Casa do Império: sociedade, cultura e política no universo doméstico da Casa Real portuguesa e da Casa Imperial do Brasil (1808-1840)
}

\section{Santiago Silva de Andrade}

Doutorando em História pela Universidade do Estado do Rio de Janeiro

\begin{abstract}
Resumo
Esta pesquisa pretende analisar o espaço doméstico do rei D. João VI e do imperador D. Pedro I, na primeira metade do século XIX. Através do estudo do numeroso grupo de homens e mulheres de todas as classes que estavam a serviço da Casa, busca-se estabelecer um quadro onde fiquem claros os referenciais que informavam o funcionamento interno da Casa Real portuguesa e da Casa Imperial do Brasil, tais como os mecanismos de admissão e remuneração dos seus criados, a relação entre a Casa e a sociedade fluminense da época e os processos de transformação que atingiram uma tradicional Casa soberana européia entre o ocaso do império luso-brasileiro e o nascimento do Império do Brasil (1808-1840)
\end{abstract}

\section{Abstract}

This research aims to analyze the domestic universe of king D. João $\mathrm{VI}$ and of emperor D. Pedro I. Through the study of numerous groups of men and women originated from different social classes that were at service in the House, it intends to unfold the references that informed the internal functioning of the Portuguese Royal House and the Imperial House of Brasil, such as the mechanisms of admission and remuneration of its servants, the relation between the House and the inhabitants of the city of Rio de Janeiro, and the processes of transformation that affected a traditional european sovereign House between the fall of the luso-brazilian Empire and the birth of the Empire of the Brazil (1808-1840)

\section{Palavras-chave}

Portugal, Brasil, Corte imperial, elites

\section{Keywords}

Portugal, Brazil, Imperial Court, elites 
Relação das pessoas que saíram desta cidade para o Brasil, em companhia da Sua Alteza Real, no dia 29 de Novembro de 1807. Lisboa, 29 de novembro de 1807. Instituto Histórico e Geográfico Brasileiro, Lata 490, Pasta 29; Arquivo Nacional do Rio de Janeiro, Fundo Negócios de Portugal, Cód. 730.
Trabalho indicado ao acesso automático ao doutorado, em setembro de 2005, no âmbito do Programa de Pós Graduação em História da UERJ.

\section{3}

Cf. Autos de um processo referente ao julgamento dos implicados na conspiração dos servidores do Paço em 15 de dezembro de 1833. Rio de Janeiro, fevereiro-março de 1835. Biblioteca Nacional do Rio de Janeiro, Seção de Mss. II$34,36,2$.

Para uma definição destas identidades políticas cf. MOREL, Marco. As transformações dos espaços públicos: imprensa, atores políticos e sociabilidades na Cidade Imperial (1820-1840). São Paulo: Hucitec, 2005. Especialmente capítulo 3.
No começo do ano de 1808, um grupo peculiar, formado por centenas de homens e mulheres, chegou ao Rio de Janeiro, acompanhando a família real portuguesa na sua travessia atlântica. Apesar das inúmeras diferenças que davam heterogeneidade àquele grupo (idade, gênero, classe social, etc), as pessoas que compunham o mesmo partilhavam de um forte elemento identitário: eram todos criados da Casa Real Portuguesa.

Cotejando alguns documentos elaborados à época do exílio brigantino, podemos arriscar que cerca de trezentos criados vieram de Portugal para o Brasil com a comitiva real ${ }^{1}$. Nas décadas posteriores esse número iria variar, tanto para cima quanto para baixo, mas até a proclamação da República, no final do século XIX, o ramo brasileiro da dinastia de Bragança manteve perto de si um núcleo relativamente numeroso de pessoas que prestavam serviços de foro privado, e que estavam ligadas a Casa Imperial do Brasil por laços de fidelidade, honra e familiares ou por simples contratos mercenários de trabalho.

Faz-se necessário esclarecer que o termo "criado" não possuía, no contexto da virada do século XVIII para o XIX, a conotação exclusivamente pejorativa que assumiu no imaginário contemporâneo. Ao invés de designar um lugar social bem definido e estabelecido, como nos dias de hoje, a denominação "criado" exprimia uma variada gama de situações que apontavam, ao fim e ao cabo, sempre para a idéia de proximidade com o monarca, sua familia e, conseqüentemente, com a Corte. Além disso, aplicava-se tanto aos membros das casas nobres que serviam ao soberano quanto aos humildes servidores dos reis, e conseqüentemente englobava múltiplas experiências sociais.

0 ponto de partida deste trabalho foi o estudo, em 2004 e em nível de mestrado2 ${ }^{2}$ da participação de alguns criados da Casa Imperial do Brasil em movimentos urbanos contestatórios ocorridos na Corte do Rio de Janeiro, entre os anos de 1831 e $1834^{3}$, no bojo das disputas entre caramurus, moderados e exaltados ${ }^{4}$. Naquela ocasião constatou-se a existência de elementos que davam uma certa coesão interna a um grupo específico de servidores ligados ao Paço, tais como o pertencimento a núcleos familiares de número restrito, a defesa de interesses comuns e o compartilhamento de uma determinada cultura de serviço, própria do universo doméstico dos monarcas portugueses. Desde o ano de 1831 acirrara-se uma campanha levada a cabo principalmente por redatores de jornais e deputados moderados e exaltados, que acusavam os criados da Casa Imperial de terem intenções restauracionistas e de conspirarem contra a recém-estabelecida direção liberal-moderada. Em outras palavras, eram acusados de serem caramurus apenas pelo fato de suas trajetórias pessoais estarem ligadas ao universo doméstico da Casa Imperial do Brasil. Na visão dos seus detratores, tal pertencimento traduzia-se na existência de laços indissolúveis entre os criados da Casa, nomeadamente aqueles mais antigos, e o ex-imperador D. Pedro I, colocando os últimos na posição de potenciais revoltosos contra o novo regime que se procurava instalar.

Nesse sentido, esta pesquisa surgiu da necessidade de se estabelecer uma melhor compreensão acerca de um grupo que não só desempenhava funções importantes dentro dos cerimoniais da corte portuguesa, garantindo, em última análise, a viabilidade dos rituais inerentes à Casa Real/ Imperial, mas que também estabeleceu diversos canais de interação com os habitantes da cidade do Rio de Janeiro e participou dos cruciais momentos 
5

Momento de construção da primeira e única Casa dinástica nascida em solo americano.

6

Para o caso inglês ver GLASHEEN, Joan. The secret people of the palaces: the royal household from the Plantagenets to Quenn Victoria. UK: Batsford, 2003.

MONTEIRO, Nuno Gonçalo Monteiro. 0 crepúsculo dos Grandes: a Casa e o patrimônio da aristocracia em Portugal (1750-1832). 2a ed. Lisboa: Imprensa Nacional/Casa da Moeda, 2003; CUNHA, Mafalda Soares da. A Casa de Bragança (1560-1640): práticas senhoriais e redes clientelares. Lisboa: Estampa, 2000.

LOURENÇO, Maria Paula Marçal. Casa, Corte e patrimônio das Rainhas de Portugal (16401754). Poderes, instituições e relações sociais. 1999. Tese (Doutorado). Faculdade de Letras, Universidade de Lisboa. Lisboa. 1999. Agradeço a Profa. Dra. Maria Paula Lourenço por sua atenção, pelas sugestões e pelos textos enviados. do esfacelamento do Império luso-brasileiro e posteriores tentativas de construção de um Estado brasileiro, entre os anos de 1808 e 1840.

Assim, esta pesquisa inicialmente contemplou dois objetivos principais:

$\left.1^{\circ}\right)$ Apreender as transformações que afetaram o espaço doméstico da Casa Real portuguesa (1808-1821) e da Casa Imperial do Brasil (1822-1840) em três momentos fundamentais para sua história: 1808-1820, quando a Casa Real portuguesa instalou-se em território colonial; 1822-1830, período no qual a Casa Real portuguesa deixou o país, e em seu lugar fundou-se a Casa Imperial do Brasil5; 1831-1840, período sui generis, no qual a abdicação do imperador D. Pedro I deixou o comando da Casa Imperial nas mãos de elementos que não possuiam vínculo consangüineo nenhum com a dinastia brigantina.

$2^{\circ}$ ) Identificar: os ofícios pertencentes ao serviço doméstico da Casa Real/Imperial; os mecanismos de recrutamento, admissão e remuneração de serviços inerentes à própria estrutura doméstica da Casa e; a estratificação hierárquica a qual estavam submetidos os criados.

As fontes selecionadas para análise são, em sua maioria, de natureza contábil/administrativa, uma vez que, ao contrário dos criados de várias Casas Reais européias, os servidores da Casa Real/Imperial do Brasil não deixaram registros pessoais significativos das suas experiências, como diários ou memórias ${ }^{6}$. Entretanto, isso não significa que o trabalho esteja prejudicado de alguma maneira; pelo contrário: a grande variedade de fontes permite o cruzamento de dados e a comparação de informações, revelando aspectos importantes das experiências coletivas e pessoais da criadagem do universo doméstico joanino e de D. Pedro I. A principal delas é o Fundo Casa Real e Imperial/Mordomia Mor, depositado no Arquivo Nacional, no Rio de Janeiro, que contém documentos relativos a diversos assuntos, como orçamentos de obras nos Paços, pedidos de mercês, correspondências administrativas entre criados, etc. Ainda no Arquivo Nacional estão vários códices relacionados a ordenação do universo doméstico da Casa: instruções para os cerimoniais, livros contábeis das Casas Real e Imperial, etc. No Museu Imperial, em Petrópolis, se encontram documentos relativos principalmente a Casa Imperial do Brasil. A Biblioteca Nacional, no Rio de Janeiro, também guarda um número importante de documentos, em sua maioria relacionados à trajetória biográfica de algumas dezenas de criados.

A análise dos documentos da Casa Real portuguesa, relativos ao período joanino (cerca de novecentos) permitiu o esclarecimento de algumas questões importantes relativas ao universo doméstico do rei D. João VI.

A primeira delas diz respeito aos mecanismos de recrutamento e admissão dos criados da Casa Real. Não há na documentação investigada nenhum texto normativo que indique de que maneira os homens e mulheres que serviriam a Casa deveriam ser escolhidos. No entanto, a mesma documentação deixa entrever alguns critérios fundamentais presentes no processo de incorporação de criados e criadas ao serviço do Paço.

Com relação à admissão dos criados que ocupavam cargos no topo da hierarquia doméstica, tais como mordomo-mor, vedor da Casa e estribeiro-mor (a elite dirigente da Casa), já foi apontado por historiadores como Nuno Gonçalo Monteiro e Mafalda Soares da Cunha, que eles eram recrutados no seio das casas nobiliárquicas de maior prestígio7. A profa. Maria Paula Lourenço também chegou a tais conclusões, como resultado da sua investigação sobre os mecanismos de acesso a Casa da rainha $D$. Maria de Áustria, no século XVIII8. No caso da corte joanina, uma rápida 
9

CUNHA, Mafalda Soares da. A Casa de Bragança (1560-1640): práticas senhoriais e redes clientelares. Lisboa: Estampa, 2000.; XAVIER, Angela Barreto; HESPANHA, Antonio Manuel. As redes clientelares. in: HESPANHA, Antonio Manuel (coord.). História de Portugal. 0 Antigo Regime (1620-1807). Lisboa: Editorial Estampa, 1998.

10

Relação das pessoas que saíram desta cidade para o Brasil, em companhia da Sua Alteza Real, no dia 29 de Novembro de 1807. Lisboa, 29 de novembro de 1807. Instituto Histórico e Geográfico Brasileiro, Lata 490, Pasta 29; Arquivo Nacional do Rio de Janeiro, Fundo Negócios de Portugal, Cód. 730.

11

Arquivo Nacional do Rio de Janeiro, Cód. 01, Vol. 01

12

Cf. SUBTIL, José. Os poderes do centro. In: HESPANHA, Antonio Manuel (coord.). História de Portugal. 0 Antigo Regime (1620-1807). Lisboa: Editorial Estampa, 1998. p.142. olhada nos quadros que compunham a elite dirigente da Casa Real pode confirmar que tais conclusões também se aplicam à corte portuguesa: estribeiro-mor, Nuno da Silva Telo e Menezes Corte Real, marquês de Vagos; mordomo-mor, D. Fernando José de Portugal e Castro, marquês de Aguar; vedor da Casa Real, o marquês de Borba. Acrescente-se que, via de regra, os detentores desses oficios maiores da Casa Real portuguesa ocupavam funções de destaque em vários nichos institucionais, seja na administração central, na vida militar ou na carreira diplomática.

Faceta muito mais difícil de se analisar, porém, é a incorporação de criados que ocupavam posições mais humildes no espaço doméstico joanino. São pessoas que deixaram pouco ou nenhum rastro, uma vez que não faziam parte do minoritário grupo de cortesãos que monopolizava os cargos mais altos da Casa. Podemos, entretanto, arriscar algumas hipóteses.

Uma delas vem dos estudos recentes sobre a estratificação social do Antigo Regime ${ }^{9}$.Podemos inferir que fazia-se imprescindivel àquele que desejasse entrar no serviço real o pertencimento a uma rede clientelar capaz de oferecer vias de acesso a Casa do rei. Em agosto de 1808, por exemplo, um certo Luís Pereira, "criado" do Marquês do Lavradio, disse que "apesar de ter apenas a obrigação do seu amo", não deixou de "servir em tudo quanto era devido as (...) Altezas que chegaram a esta Corte", e lembrava que era "costume que quando um vassalo tem a honra de servir as Pessoas Reais e entrar em sua Real Câmara V.A.R Ihe faz a graça de os nomear Criados". Luís Pereira pedia, então, ser nomeado Moço da Prata, fazendo uso, assim, do trânsito que desfrutava como resultado dos serviços prestados a um membro importante da Corte portuguesa. Por outro lado, a manutenção de relações de subordinação de tipo tradicional encontrava no universo doméstico da Casa Real uma importante fonte de esteio.

Apesar de não haver garantias de que os criados das Casas nobres portuguesas fossem automaticamente admitidos no serviço da Casa Real com o passar do tempo, não era incomum que cortesãos recomendassem membros do seu séquito particular a D. João VI. Podemos testar a validade de tal afirmação através do cruzamento de dados oriundos da lista de passageiros que vieram para o Rio de Janeiro com a Corte $^{10}$, em 1808, e os nomes presentes nos registros de pagamentos feitos aos criados da Casa Real ${ }^{11}$. Entre 1808 e 1820, vários homens e mulheres que constavam, no primeiro ano, como "criados" de Casas nobres, conseguiram ser admitidos no espaço doméstico joanino ao longo da década de 1810 ou, em alguns casos, conseguiram posicionar seus filhos ou filhas no serviço da Casa Real.

Uma segunda forma de acesso ao serviço do Paço, e talvez a mais tradicional, foi a transmissão hereditária dos cargos. Apesar das evidências de que nem todo descendente de criado se tornaria criado também, é possivel encontrar familias inteiras servindo a Casa Real, de forma contínua e ininterrupta, desde pelo menos o começo do século XVIII. Isto ocorria não apenas na pequena elite doméstica, mas era um padrão que se espalhava por toda a hierarquia da Casa: o exercício de uma certa tradição, associada a uma imagem de pertencimento a um núcleo familiar com sólidos laços de fidelidade estabelecidos com a Casa fornecia, aos que compartilhavam as diversas modalidades da presença do rei, um forte sentimento de coesão ao universo doméstico do soberano. Aos olhos de quem estava de fora tudo parecia segredo e mistério ${ }^{12}$.

Contrastando as flutuações orçamentárias da Casa Real portuguesa, entre os anos de 1808 e 1821, e o movimento de expansão do número de 
13

Despensa da Casa Real

14

Arquivo Nacional. Casa Real e Imperial Mordomia Mor. Caixa 3, Pacote 3, Doc. 255.

15

Arquivo Nacional. Casa Real e Imperial Mordomia Mor. Caixa 3, Pacote 3, Doc. 261 criados da Casa (o que poderíamos classificar de expansão da rede clientelar do universo doméstico), podemos perceber que, apesar do déficit ter pulado de 10:578 \$526 (dez contos, quinhentos e setenta e oito mil e quinhentos e vinte e seis réis)em 1808 para 239:049\$846 (duzentos e trinta de nove contos, quarenta e nove mil e oitocentos e quarenta e seis réis) em 1821, dois principios norteavam a ação da elite dirigente da Casa Real portuguesa enquanto esteve no Brasil: reproduzir, no espaço historicamente colonial, o processo de expansão e manutenção de uma extensa rede de dependentes do universo doméstico joanino, algo que já vinha sendo praticado desde pelo menos o começo do século XVIII, em Portugal; e preservar uma imagem e memória que vinculassem a Casa a uma idéia de opulência e poder na nova Corte que se estabeleceu no Rio de Janeiro.

Enquanto esteve no Brasil, a Casa Real portuguesa - através da sua elite governativa - logrou êxito em sustentar uma rede de dependentes residentes em ambos os lados do atlântico. Cerca de trezentos criados aportaram no Rio de Janeiro com a Corte, em 1808, e ao longo do período joanino esse número aumentou cerca de sessenta por cento (porcentagem relativa aos que residiam no Rio de Janeiro e que efetivamente estavam a serviço da Casa), não computadas, aqui, aquelas pessoas que residiam em Portugal e recebiam algum benefício da Casa Real. Assim, à Casa Real portuguesa afluiam reivindicações de dois grupos que, apesar de compartiIharem elementos peculiares à conformação da sua identidade, vivenciavam experiências históricas distintas. Tal situação era mais uma característica da nova circunstância histórica que se abatera sobre Portugal e sobre a dinastia dos Bragança desde a invasão da península ibérica pelas tropas napoleônicas no começo do século XIX.

Em 1821, com a partida de D. João VI para Portugal, a situação dos criados da Casa Real tornou-se indefinida. Os laços de fidelidade no universo doméstico joanino privilegiavam a figura do rei, associando à sua presença a existência de um espaço cortesão ou da própria Casa Real. Não foi por outro motivo que, poucos dias antes de embarcar, D. João VI recebeu uma carta de José Antonio Manoel, criado da Casa Real "dos mais antigos", suplicando uma "licença para ir nesta expedição para Portugal" e afirmando que "a Real Ucharia13 acaba pela partida de Vossa Majestade e que fica [o suplicante] em desamparo". José Manoel implorava que o mandasse "ir agora para Lisboa (...) ou em serviço ou como Vossa Majestade for servido mandar, pois o suplicante de maneira alguma quer ficar nesta terra, porque certo fica desgraçado"14.

0 pedido do criado José Manoel fazia sentido. Servindo à Casa Real há mais de quarenta anos,ou seja, desde 1780, era completamente dependente dos mecanismos compensatórios inerentes a estrutura doméstica joanina. Em outras palavras, e sob seu próprio ponto de vista, sua vida estava atrelada aos destinos da Casa Real portuguesa.

Outras criados, no entanto, desfrutavam de mais opções naquele momento.

Uma semana após a partida de D. João VI, mais especificamente no dia 28 de abril de 1821, o Barão do Rio Seco, Tesoureiro da Casa Real e figura influente nos assuntos da Casa, escreveu ao jovem príncipe D. Pedro, desejando mostrar "obediência a Sua Alteza Real e desejar-Ihe acertar em tudo o que for do Seu Real Serviço"15.

Comparando os depoimentos do criado José Antonio Manoel e do Barão do Rio Seco, podemos perceber que se ao primeiro a Casa e a Corte 
16

Arquivo Nacional. Casa Real e Imperial

Mordomia Mor. Caixa 3, Pacote 3, Doc. 266 reais realizavam-se na figura do rei D. João $\mathrm{VI}$, como se a presença do soberano sacralizasse o espaço que ocupava, ao segundo um leque maior de opções estava aberto, resultado muito provavelmente da sua segura posição social e financeira.

0 biênio 1821-1822 significou, para aqueles que efetivamente dependiam da estrutura doméstica joanina, um período de redefinição dos laços de fidelidade que os uniam ao serviço do Paço. Frente a um período de incertezas detonado pelo movimento vintista, os criados da Casa Real viram-se mais uma vez, como em 1807, diante da possibilidade de esfacelamento de direitos garantidos pela existência da estrutura doméstica a qual estavam ligados.

Tais afirmações nos levam a outro problema, a saber: o processo de rompimento com o universo doméstico do seu pai, por parte do imperador D. Pedro I, e posterior fundação da Casa Imperial do Brasil, entre 1822 e 1825.

Ao historiador disposto em aventurar-se a investigar as supostas "origens" da Casa Imperial do Brasil, um aviso: há que se contentar mais com indícios do que com fatos, mais com pistas do que com provas. Tal constatação surgiu no decorrer da pesquisa, ao comparar a farta massa documental produzida pela administração da Casa Real portuguesa no Rio de Janeiro, entre 1808 e 1821 (algo próximo de novecentos documentos, com afirmado anteriormente), e os parcos registros do universo doméstico da Casa Imperial do Brasil, entre 1822 e 1825 (pouco mais de oito dezenas de documentos). Como explicar tal fenômeno? Em teoria, poderíamos dizer que o surgimento da Casa Imperial do Brasil se deu quando proclamou-se a independência, em 1822, mas estudos recentes têm ressaltado a complexidade daquele momento histórico, não mais reduzindo-o ao suposto marco fundador de sete de setembro. Estes mesmos estudos têm apontado para a existência de espaços de continuidade que conectavam a construção de um Estado brasileiro à sua condição histórica de ex-centro do Império português, enfatizando características de natureza hibrida, limitadas tanto pela herança do Antigo Regime quanto pela novidade das propostas de cunho "modernizante".

Desde a partida do seu pai para Portugal, D. Pedro procurou imprimir a sua marca pessoal aos negócios da Casa. Em primeiro lugar, com o intuito de enxugar as dividas da Casa, que naquele momento orçavam perto de 300:000\$000 (trezentos contos de réis), ordenou, em setembro de 1821, a todos os responsáveis pelas repartições (Ucharia, Reais Cavalariças, etc) da Casa Real que the remetessem listas contendo os nomes das pessoas que recebiam pensões por tais repartições. A maioria esmagadora era de viúvas e órfãs de Criados da Casa Real, e no dia 2 de setembro daquele mesmo ano D. Pedro determinou que todas as pensões pagas pela Casa Real passassem a ser pagas diretamente através do Tesouro Público, e não mais pelas repartições da Casa, como acontecia desde, pelo menos, o século XV, nas Cortes reais ibéricas ${ }^{16}$. Ao contrário do que geralmente se pensa, o Erário Régio e o cofre da Casa Real não eram a mesma coisa, e era o primeiro que fornecia o dinheiro necessário às despesas do segundo. Com essa medida, D. Pedro transferia diretamente para o Estado uma despesa anual de aproximadamente 12:000\$000 (doze contos de réis), desonerando, em tese, a folha de pagamento da Casa Real e limitando, parcialmente, os possiveis requerimentos de um grande número de dependentes da sua estrutura doméstica.

Em maio de 1821, o imperador D. Pedro mandou demitir quarenta e dois Moços da Água, sessenta e seis serventes do Paço e dezoito varredeiras, mantendo em serviço apenas 12 homens e mulheres, de um grupo 
Arquivo Nacional. Casa Real e Imperial Mordomia Mor. Caixa 3, Pacote 3, Doc. 265

18

Arquivo Nacional. Casa Real e Imperial. Cód. 1, Vol. 1, folha $211-212$ original de 134 pessoas do mais baixo escalão da Casa Real ${ }^{17}$. Em 19 de novembro do mesmo ano foi emitida uma ordem ao Tesoureiro da Casa contendo nomes de trinta Criados que a partir daquele momento deveriam ter seus ordenados pagos diretamente pela datação destinada ao Príncipe, e não mais diretamente pela Casa Real18.

Podemos já afirmar, com base na pesquisa realizada, que a fundação da Casa Imperial do Brasil não é fruto exclusivo dos ímpetos autonomistas do imperador D. Pedro I, já que toda a sua estrutura manteve-se calcada na experiência da Casa Real portuguesa. Os modelos cerimoniais, a estratificação hierárquica, a nomenclatura dos cargos e a divisão de tarefas no interior do espaço doméstico do imperador permaneceram fiéis ao modelo da Casa portuguesa, já considerado arcaico no século XIX em comparação à outras Casas reais européias. Os textos normativos, em sua maioria dos séculos XVI e XVII, que serviram de base à Casa Real portuguesa, permaneceram como fontes legislativas quando o assunto era a criadagem da Casa Imperial, e até o final do século XIX não se produziu nenhuma grande novidade em termos de instrumentos organizacionais do espaço doméstico.

Mesmo assim, os criados não deixaram de ser assunto das preocupações do imperador D. Pedro I. A Constituição de 1824 também fez referência aos Criados da Casa Imperial. 0 inciso III, do artigo 92, capitulo VI, título IV da Constituição de 1824, com relação aos impedimentos de votar nas Assembléias Paroquiais, dizia: "[São excluídos de votar] os Criados da Casa Imperial que não forem de galão branco", o mesmo se aplicando para os casos de candidatura aos postos de deputado ou senador. Como se sabe, o galão é uma tira de tecido bordado usado na mangas das fardas, ou nos chapéus, de algumas categorias de funcionários do Império. Apenas uma investigação posterior poderá esclarecer melhor a quem interessava, no momento da elaboração da Constituição de 1824, excluir um grande número de Criados do processo eleitoral. À primeira vista, o próprio Imperador D. Pedro I resolveu limitar a capacidade de manobra política da sua criadagem, talvez antevendo o envolvimento destes últimos com possíveis adversários seus.

Resta saber, agora, quais as transformações mais radicais que atingiram o modelo organizacional da Casa Imperial após a abdicação do imperador, em 1831. Comandada por elementos civis que não tinham procedência aristocrática portuguesa, a Casa Imperial, que ainda guardava inúmeras semelhanças com a Casa Real portuguesa, estava prestes a entrar no xadrez político dos grupos que chegaram ao poder no vácuo de poder criado pela abdicação. A documentação referente ao periodo deixa antever, num rápido exame, um período difícil para os criados da Casa, alguns deles em serviço há mais de cinqüenta anos: demissões, substituições e cortes de ordenados foram algumas das primeiras providências tomadas pelos adversários do ex-imperador assim que assumiram o controle do Paço.

Recebido para publicação em

janeiro de 2007

Aprovado em março de 2007 